University of Nebraska - Lincoln

DigitalCommons@University of Nebraska - Lincoln

12-20-1999

\title{
Nanocomposite CoPt:C films for extremely high-density recording
}

M. Yu

University of Nebraska - Lincoln

Yi Liu

University of Nebraska-Lincoln, yliu@unl.edu

A. Moser

IBM Almaden Research Center, San Jose, California

D. Weller

IBM Almaden Research Center, San Jose, California

David J. Sellmyer

University of Nebraska-Lincoln, dsellmyer@unl.edu

Follow this and additional works at: https://digitalcommons.unl.edu/physicssellmyer

Part of the Physics Commons

Yu, M.; Liu, Yi; Moser, A.; Weller, D.; and Sellmyer, David J., "Nanocomposite CoPt:C films for extremely high-density recording" (1999). David Sellmyer Publications. 68.

https://digitalcommons.unl.edu/physicssellmyer/68

This Article is brought to you for free and open access by the Research Papers in Physics and Astronomy at DigitalCommons@University of Nebraska - Lincoln. It has been accepted for inclusion in David Sellmyer Publications by an authorized administrator of DigitalCommons@University of Nebraska - Lincoln. 


\title{
Nanocomposite CoPt:C films for extremely high-density recording
}

\author{
M. Yu ${ }^{\text {a) }}$ and Y. Liu ${ }^{\text {b) }}$ \\ Center for Materials Research and Analysis, University of Nebraska, Lincoln, Nebraska 68588-0113
}

A. Moser and D. Weller

IBM Almaden Research Center, 650 Harry Road, San Jose, California 95120

D. J. Sellmyer ${ }^{\mathrm{a}), \mathrm{c})}$

Center for Materials Research and Analysis, University of Nebraska, Lincoln, Nebraska 68588-0113

(Received 26 May 1999; accepted for publication 26 October 1999)

\begin{abstract}
Nanocomposite CoPt:C films were investigated as potential media for extremely high-density recording. An annealing temperature of over $600{ }^{\circ} \mathrm{C}$ is necessary to form nanocomposite CoPt:C films consisting of $\mathrm{C}$ matrix and fct CoPt nanocrystallites with grain sizes of $8-20 \mathrm{~nm}$ and coercivities of 3-12 kOe. Coercivity and grain size increase with increasing annealing temperature and decreasing $\mathrm{C}$ concentration and they are insensitive to film thickness. The average activation volumes are about $0.9 \times 10^{-18} \mathrm{~cm}^{3}$. The properties of these nanocomposite $\mathrm{CoPt}: \mathrm{C}$ films can be tailored to satisfy the thermal stability, coercivity, and media noise requirements for extremely high-density recording. (C) 1999 American Institute of Physics. [S0003-6951(99)00951-1]
\end{abstract}

The areal density of longitudinal magnetic recording has been increasing $60 \%$ annually and the trend is predicted to continue in the near future. ${ }^{1-3}$ At present, using Co-based media, areal density of more than $10 \mathrm{~Gb} / \mathrm{in}^{2}$ has been achieved in commercial hard-disk drives and several 20 Gb/in. ${ }^{2}$ and above demonstrations were reported recently. ${ }^{4}$ Extremely high-density recording (EHDR), defined here as an areal density of about $100 \mathrm{~Gb} / \mathrm{in}^{2}$, is sought for implementation in a few years. In order to have low media noise, EHDR media would need to have coercivity $\left(H_{c}\right)$ of about 4 kOe (Ref. 5) and weakly exchange-coupled grains of less than $10 \mathrm{~nm}$ in size according to very simple estimates. ${ }^{6}$

For grain size $d \approx 10 \mathrm{~nm}\left(V \approx d^{3}=1 \times 10^{-18} \mathrm{~cm}^{3}\right)$, the issue of thermal stability has to be considered. The magnetization of a grain decays due to thermal fluctuations. At temperature $T$ the relaxation time $\tau$ is given by ${ }^{7}$

$$
1 / \tau=f_{0} \exp \left(-E_{B} / k_{B} T\right),
$$

where $f_{0}\left(\sim 10^{9} \mathrm{~Hz}\right)$ is the attempt frequency and $E_{B}$ is the energy barrier, a function of applied field $H$. Based on the Stoner-Wohlfarth (SW) model with a low-field approximation, it can be shown that

$$
E_{B}=K_{u} V\left(1-H / H_{A}\right) \approx K_{u} V,
$$

where $V$ is the grain volume, $K_{u}$ is the uniaxial anisotropy constant, and $H_{A}=2 K_{u} / M_{s}$ is the anisotropy field $\left(M_{s}\right.$ is the saturation magnetization). It is usually required that the relaxation time of the grains in recording media be at least ten years. Thus, from Eqs. (1) and (2) it is required that $K_{u} V / k_{B} T>40$. This requirement increases to

$$
K_{u} V / k_{B} T>60
$$

in a typical $40 \mathrm{~Gb} / \mathrm{in}^{2}{ }^{2}$ recording environment, ${ }^{8}$ due to nonnegligible interbit stray fields. For Co-based media, $K_{u} \approx 2$

\footnotetext{
a) Also at the Behlen Laboratory of Physics.

b) Also at the Department of Mechanical Engineering.

c)Electronic mail: dsellmyer1@unl.edu
}

$\times 10^{6} \mathrm{erg} / \mathrm{cm}^{3}$. As grain sizes become smaller than $10 \mathrm{~nm}$, it is clear that Eq. (3) cannot be satisfied at room temperature. So, it is interesting to investigate media materials with $K_{u}$ higher than that of Co-based media.

The ordered fct CoPt phase has $K_{u} \approx 5 \times 10^{7} \mathrm{erg} / \mathrm{cm}^{3}$, thus Eq. (3) can be well satisfied even with $d=4 \mathrm{~nm}$ ( $V$ $=6.4 \times 10^{-20} \mathrm{~cm}^{3}$ ). Large $H_{c}$, which originate from the high $K_{u}$ value, were reported in CoPt bulk samples, ${ }^{9} \mathrm{CoPt}$ films, ${ }^{10}$ $\mathrm{CoPt}$ nanoparticulates grown on quartz substrates, ${ }^{11}$ and $\mathrm{CoPt} / \mathrm{Ag}$ films. ${ }^{12}$ For the purpose of forming small $\mathrm{CoPt}$ grains with weak exchange coupling, $\mathrm{C}$ would be an ideal isolation material between neighboring CoPt grains because there exist neither stable Co nor Pt carbides.

A real magnetic film, such as a recording medium, is generally very different from a collection of identical isolated SW grains because of intergrain interactions, grain-size distribution, and incoherent rotation in magnetization reversal. For such a system, Eq. (3) is generally not applicable since $E_{B}(H)$ is different from Eq. (2). The magnetic activation volume $V^{*}$ can be regarded as the effective or average unit volume of magnetic moments that switch together in magnetization reversal regardless of the magnetization reversal model. ${ }^{13,14}$ This idea is supported by the fact that media noise for Co-based films is proportional to $M_{s} V^{*} .{ }^{15}$ It can be shown that ${ }^{6,16}$

$$
V^{*}=-\left(\partial E_{B} / \partial H\right) / M_{s} .
$$

For isolated identical SW grains, $V^{*} \approx V$ if $H \ll H_{A}$. For a real system, Eq. (4) shows that $V^{*}$ is not directly related to $V$, but rather depends explicitly on $E_{B}(H)$. Nevertheless, it is $V^{*}$ instead of $V$ that should be considered in thermal relaxation, so that $V$ in Eq. (3) should be replaced by $V^{*} .{ }^{6}$ In this letter, $V^{*}$ was derived from its relationship with magnetic viscosity and irreversible susceptibility. ${ }^{14,17}$

$\mathrm{CoPt}: \mathrm{C}$ films were cosputtered onto water-cooled $\mathrm{Si}(100)$ substrates from pure $\mathrm{Co}, \mathrm{Pt}$, and $\mathrm{C}$ targets. The atomic ratio of $\mathrm{Co}$ and $\mathrm{Pt}$ is fixed at $1: 1$ and the $\mathrm{C}$ concentration ranges from 30 to $80 \mathrm{vol} \%$. The base pressure is 


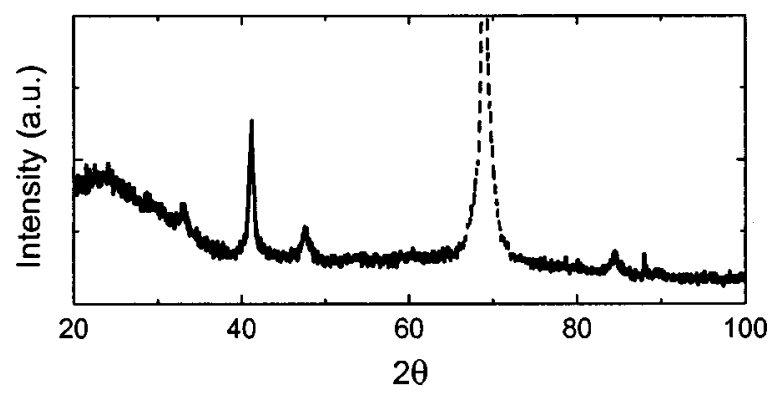

FIG. 1. XRD patterns of a $100 \mathrm{~nm}$ CoPt:C film with $30 \mathrm{vol} \% \mathrm{C}$ annealed at $650{ }^{\circ} \mathrm{C}$. The peak of the dashed line is from the $\mathrm{Si}(100)$ substrate.

better than $3 \times 10^{-7}$ Torr and the Ar pressure is 10 mTorr. The thickness of CoPt:C film is varied from 3 to $100 \mathrm{~nm}$ and the $\mathrm{C}$ underlayer and overcoat are both $20 \mathrm{~nm}$. All asdeposited films were annealed in vacuum for $1 \mathrm{~h}$ at various temperatures. The structural properties were analyzed by $\mathrm{x}$-ray diffraction (XRD) and transmission electron microscopy (TEM). The magnetic measurements were performed on an alternating gradient force magnetometer and a superconducting quantum interference device magnetometer parallel to the film plane unless specified otherwise. The recording experiments were carried out on small sample pieces using a drag tester.

All as-deposited films are magnetically soft with $H_{c}$ less than 100 Oe. They most likely consist of disordered fcc $\mathrm{CoPt},{ }^{9-12}$ which is the high-temperature phase, and/or amorphous CoPt in addition to $\mathrm{C}$ matrix. Since fct $\mathrm{CoPt}$ is the low-temperature phase, appropriate annealing leads to the transition from the fcc CoPt phase to the fct CoPt phase in CoPt:C films. As a typical example, Fig. 1 shows the XRD patterns of $100 \mathrm{~nm} \mathrm{CoPt:C}$ films with $30 \mathrm{vol} \% \mathrm{C}$ annealed at $650^{\circ} \mathrm{C}$. Excluding the peak from the $\mathrm{Si}(100)$ substrate (dashed line at $2 \theta=69.2^{\circ}$ ), all visible peaks can be attributed to the fcc CoPt or fct CoPt phase. This indicates that most $\mathrm{C}$ remains as a pure element matrix rather than forming any carbide phases. The grain size $d$ is about $12 \mathrm{~nm}$, as estimated by Scherrer's formula ${ }^{18}$ from the (111) peak width. It is difficult to distinguish between fct CoPt and fcc CoPt phases only from XRD measurement because their XRD patterns are very similar and all peaks are considerably broadened due to the very small grain sizes. The development of large $H_{c}$ can best indicate the formation of the fct CoPt phase. The annealing temperature $\left(T_{A}\right)$ dependence of $H_{c}$ and $d$ of 100

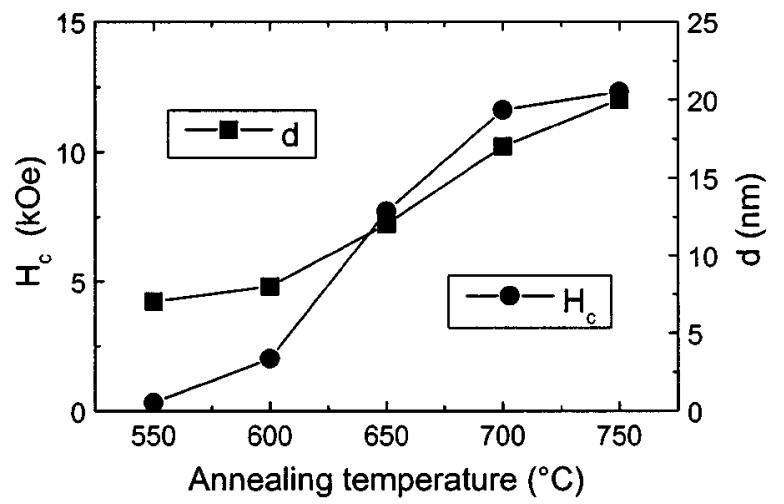

FIG. 2. $H_{c}$ and $d$ of $100 \mathrm{~nm}$ CoPt:C films with $30 \mathrm{vol} \% \mathrm{C}$ annealed at various temperatures.

Downloaded 17 Nov 2006 to 129.93.16.206. Redistribution subject to AIP license or copyright, see http://apl.aip.org/apl/copyright.jsp

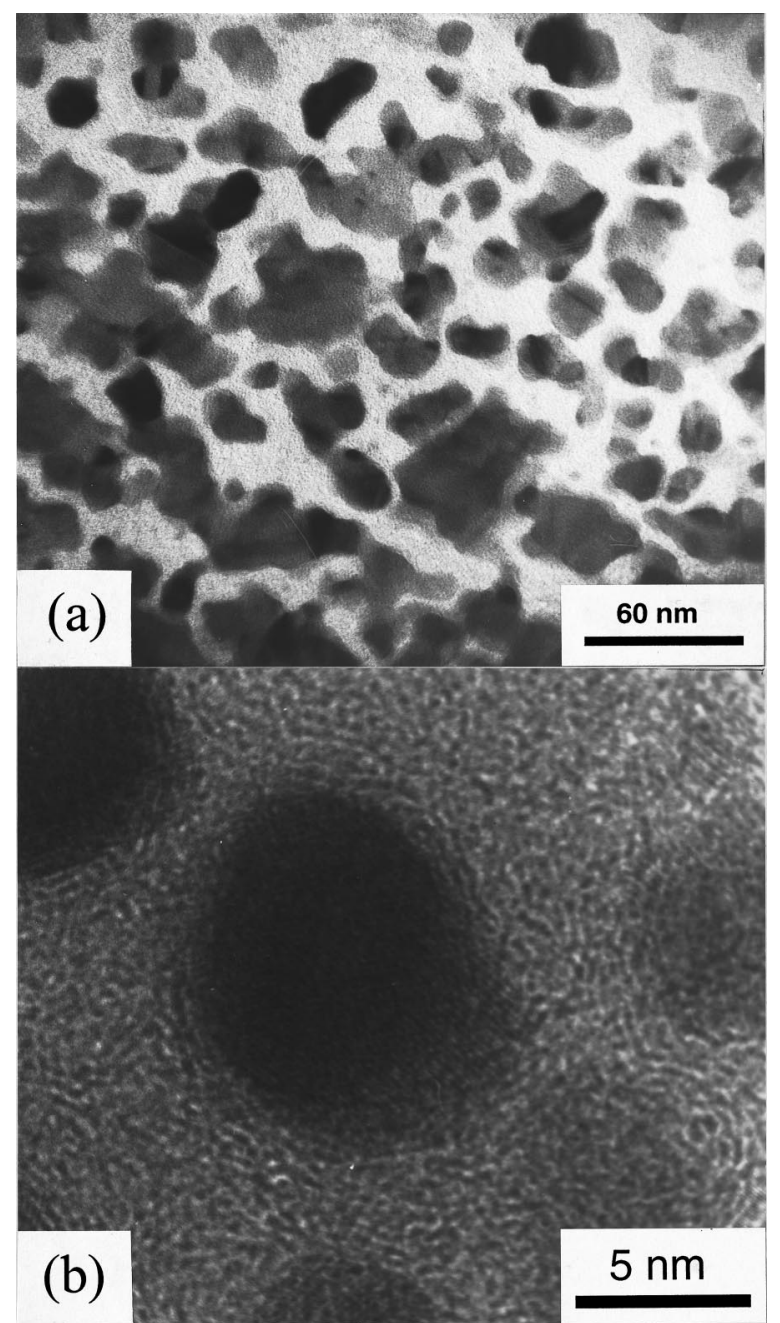

FIG. 3. (a) Bright-field and (b) high-resolution TEM pictures of a $100 \mathrm{~nm}$ CoPt:C film with 30 vol $\% \mathrm{C}$ annealed at $650^{\circ} \mathrm{C}$.

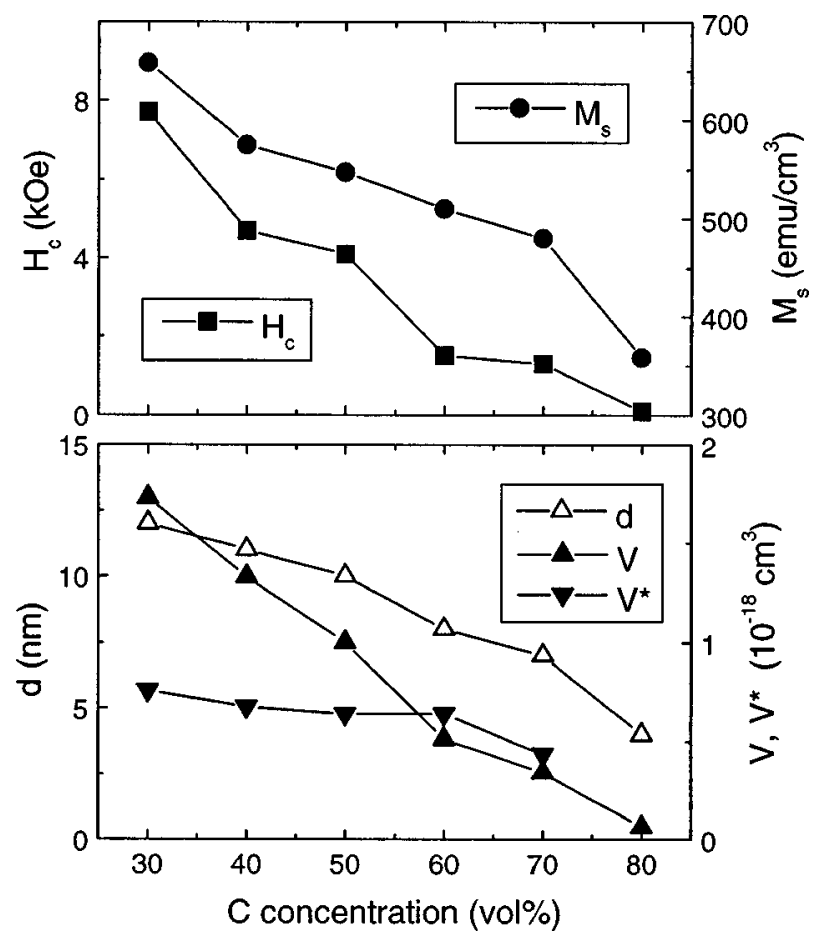
FIG. 4. $H_{c}, M_{s}, d, V=d^{3}$, and $V^{*}$ of $100 \mathrm{~nm}$ CoPt:C films annealed at
$6500^{\circ} \mathrm{C}$ with various $\mathrm{C}$ concentrations. AlP license or copyright, see http://apl.aip.org/apl/copyright.jsp 


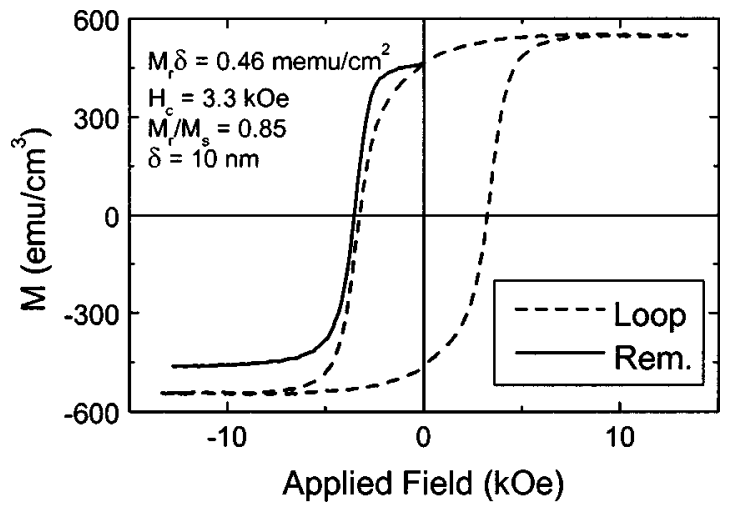

FIG. 5. Hysteresis loop and dc remanence curve of a $10 \mathrm{~nm} \mathrm{CoPt:C} \mathrm{film}$ with 50 vol $\% \mathrm{C}$ annealed at $600^{\circ} \mathrm{C}$.

nm CoPt:C films with 30 vol \% C are plotted in Fig. 2. While $d$ increases steadily with increasing $T_{A}, H_{C}$ increases first dramatically, from 2.0 to $11.9 \mathrm{kOe}$, when $T_{A}$ increases from 600 to $700{ }^{\circ} \mathrm{C}$, then slowly when $T_{A}$ is further increased. The rapid increase of $H_{c}$ around $T_{A}$ of $650^{\circ} \mathrm{C}$ can be explained only by the formation of the fct $\mathrm{CoPt}$ phase. The slow increase of $H_{c}$ when $T_{A}$ is higher than $700^{\circ} \mathrm{C}$ is most likely due to the growth of fct CoPt crystallites.

Figure 3(a) is a bright-field TEM image of a $100 \mathrm{~nm}$ CoPt:C film with 30 vol $\% \mathrm{C}$ annealed at $650^{\circ} \mathrm{C}$. Some CoPt grains are well separated from each other while some appear aggregated. Figure $3(\mathrm{~b})$ is a high-resolution TEM image showing a CoPt grain separated from others. This image also shows that the $\mathrm{C}$ matrix is amorphous and the $\mathrm{CoPt}$ grain is a single crystal. The average grain size observed from Fig. 3 is about $11 \mathrm{~nm}$, which is in good agreement with the result obtained from Scherrer's formula.

The effect of $\mathrm{C}$ concentration was investigated for CoPt:C films annealed at $650{ }^{\circ} \mathrm{C}$. Figure 4 shows $H_{c}, M_{s}$, and $d$, along with $V=d^{3}$, and $V^{*}$ of $100 \mathrm{~nm}$ films as functions of $\mathrm{C}$ concentration. As expected, $M_{s}$ decreases almost linearly with increasing $\mathrm{C}$ concentration. So does $d$ because more $\mathrm{C}$ certainly slows the growth of $\mathrm{CoPt}$ grains. Presumably, the primary reason for the decrease of $H_{c}$ with increasing C concentration is due to a decreasing $K_{u}$ value resulting from incomplete transition from the fcc CoPt phase to the fct CoPt phase. The decrease of $d$ may also contribute to the decrease of $H_{c}$. For $\mathrm{C}$ concentration of less than $60 \mathrm{vol} \%$, $V^{*}$ is almost constant, at about $0.68 \times 10^{-18} \mathrm{~cm}^{3}$, and it is considerably smaller than $V$, suggesting incoherent rotations. For higher $\mathrm{C}$ concentrations $V^{*}$ is close to $V$ and decreases with $\mathrm{C}$ concentration.

A large variation of film thickness $\delta$ has little effect on $H_{c}$ and $V^{*}$ of annealed CoPt:C films. For those with 50 vol \% $\mathrm{C}$ annealed at $600{ }^{\circ} \mathrm{C}, H_{c}$ remains almost constant, at about $3.3 \pm 0.7 \mathrm{kOe}$ when $\delta \geqslant 5 \mathrm{~nm}$. When $\delta=3 \mathrm{~nm}, H_{c}$ decreases to $1.5 \mathrm{kOe}$, probably resulting from the decreased grain volume due to reduced dimension. $V^{*}$ appears to be a constant, at about $(1.1 \pm 0.1) \times 10^{-18} \mathrm{~cm}^{3}$, for the whole thickness range $(\delta=3-100 \mathrm{~nm})$.

Recording experiments were performed on selected samples. The results of a $10 \mathrm{~nm} \mathrm{CoPt:C}$ film with $50 \mathrm{vol} \% \mathrm{C}$

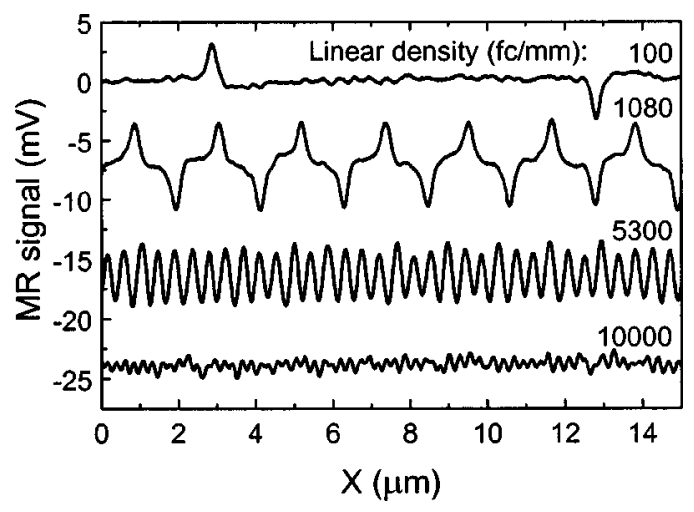

FIG. 6. Magnetoresistance (MR) head read-back signals of individual tracks at various linear densities of a $10 \mathrm{~nm} \mathrm{CoPt:C} \mathrm{film} \mathrm{with} 50 \mathrm{vol} \% \mathrm{C}$ annealed at $600{ }^{\circ} \mathrm{C}(\mathrm{X}$ denotes the distance along the track direction).

annealed at $600{ }^{\circ} \mathrm{C}$ are given here as an example. This sample has $d<10 \mathrm{~nm}$ and $V^{*} \approx 1.1 \times 10^{-18} \mathrm{~cm}^{3}$. The hysteresis loop and dc remanence curve are shown in Fig. 5. The read-back signals of individual tracks at various linear densities are shown in Fig. 6. With a C overcoat of $20 \mathrm{~nm}$, clear read-back signals at linear densities of at least $5000 \mathrm{fc} / \mathrm{mm}$ can be obtained. Much higher densities may be expected if the $\mathrm{C}$ overcoat thickness is reduced to less than $10 \mathrm{~nm}$.

In summary, we are able to synthesize nanocomposite CoPt:C films with controlled nanostructure and magnetic properties so that parameters suitable for EHDR media can be obtained. In addition, both $\mathrm{CoPt}$ and $\mathrm{C}$ phases have excellent chemical stability. Therefore, nanocomposite CoPt:C film is a very promising media candidate for extremely highdensity recording.

The authors thank Professor S. H. Liou and C. P. Luo for their generous help. This work is supported by NSIC and NSF/DMR-9623992.

${ }^{1}$ E. Grochowski and D. A. Thompson, IEEE Trans. Magn. 30, 3797 (1995).

${ }^{2}$ J. L. Simonds, Phys. Today 48, 26 (1995).

${ }^{3}$ D. N. Lambeth, D. E. Laughlin, S. Charap, L.-L. Lee, P. Harllee, and L. Tang, NATO ASI Ser., Ser. E, 767 (1997).

${ }^{4}$ Data Storage, 6, 8 (1999).

${ }^{5} \mathrm{H}$. N. Bertram (private communication).

${ }^{6}$ D. J. Sellmyer, M. Yu, and R. D. Kirby, Nanostruct. Mater. 12, 1021 (1999).

${ }^{7}$ L. Néel, Ann. Geophys. (C.N.R.S.) 5, 99 (1949).

${ }^{8}$ S. H. Charap, P.-L. Lu, and Y. He, IEEE Trans. Magn. 33, 978 (1997).

${ }^{9}$ R. A. McCurrie and P. Gaunt, Philos. Mag. 13, 567 (1966).

${ }^{10}$ K. R. Coffey, M. A. Parker, and J. K. Howard, IEEE Trans. Magn. 31, 2737 (1995).

${ }^{11}$ S. H. Liou, Y. Liu, S. S. Malhotra, M. Yu, and D. J. Sellmyer, J. Appl. Phys. 79, 5060 (1996).

${ }^{12}$ S. Stavroyiannis, I. Panagiotopoulos, D. Niarchos, J. A. Christodoulides, Y. Zhang, and G. C. Hadjipanayis, Appl. Phys. Lett. 73, 3453 (1998).

${ }^{13}$ E. P. Wohlfarth, J. Phys. F 14, L155 (1984).

${ }^{14}$ D. Givord, Q. Lu, M. F. Rossignol, P. Tenaud, and T. Viadieu, J. Magn. Magn. Mater. 83, 183 (1990).

${ }^{15}$ K. Yamanaka, T. Yamamoto, K. Tanahashi, N. Inaba, Y. Hosoe, Y. Uesaka, and M. Futamoto, J. Magn. Magn. Mater. 152, 411 (1996).

${ }^{16}$ D. Givord, A. Lienard, P. Tenaud, and T. Viadieu, J. Magn. Magn. Mater. 67, L281 (1987).

${ }^{17}$ R. Street and J. C. Woolley, Proc. Phys. Soc., London, Sect. A 62, 562 (1949).

${ }^{18}$ B. D. Cullity, Elements of X-ray Diffraction, 2nd ed. (Addison-Wesley, Reading, MA, 1978), p. 102. 